\title{
Lineage, Temperature, and Host Species have Interacting Effects on Lesion Development in Phytophthora ramorum
}

C. A. Eyre, Forest Pathology and Mycology Laboratory, Department of Environmental Science, Policy and Management, University of California-Berkeley, Berkeley; K. J. Hayden, Forest Pathology and Mycology Laboratory, Department of Environmental Science, Policy and Management, University of California-Berkeley; INRA, Interactions Arbres-Microorganismes, UMR1136, F-54280 Champenoux, France; and Université de Lorraine, Interactions Arbres-Microorganismes, UMR1136, F-54500 Vandoeuvre-lès-Nancy, France; M. Kozanitas, Forest Pathology and Mycology Laboratory, Department of Environmental Science, Policy and Management, University of California-Berkeley; N. J. Grünwald, Horticultural Crops Research Laboratory, United States Department of Agriculture-Agricultural Research Service, Corvallis, OR; and M. Garbelotto, Forest Pathology and Mycology Laboratory, Department of Environmental Science, Policy and Management, University of California-Berkeley

\begin{abstract}
Eyre, C. A., Hayden, K. J., Kozanitas, M., Grünwald, N. J., and Garbelotto, M. 2014. Lineage, temperature, and host species have interacting effects on lesion development in Phytophthora ramorum. Plant Dis. 98:1717-1727.

There are four recognized clonal lineages of the pathogen Phytophthora ramorum. The two major lineages present in North America are NA1 and NA2. With a few exceptions, NA1 is found in natural forest ecosystems and nurseries, and NA2 is generally restricted to nurseries. Isolates from the NA1 and NA2 lineages were used to infect rhododendron, camellia, and California bay laurel in detached leaf assays to study the effects of lineage, temperature, and host on pathogenicity and host susceptibility. Isolates within both lineages

was also a tendency toward reduced lesion size in successive trials, suggesting degeneration of isolates over time. Temperature had a significant effect on lesion size, with a response that varied depending on the host and isolate. Phenotypic differences between lineages appear to be heavily influenced by the representation of isolates used, host, and temperature. The importance of temperature, host, and lineage are discussed with respect to disease management, as well as future range expansions and migrations of the pathogen.
\end{abstract} were highly variable in their ability to form lesions on each host. There
Phytophthora ramorum is an emergent generalist Oomycete pathogen (Kingdom: Stramenopila) causing sudden oak death in the United States $(62,76)$, sudden larch death in the United Kingdom $(4,73)$, and ramorum blight in both the United States and Europe $(5,12,34,63,76)$. The origins of $P$. ramorum are unknown but genetic evidence suggests it to be an exotic pathogen introduced to North America and Europe on multiple occasions via the commercial nursery industry $(11,26-28,43,52,53)$, and potentially originating from Asia (8). P. ramorum is heterothallic, with two mating types (A1 and A2). Although sexual reproduction is possible, it is thought to be rare, and the two mating types are generally geographically separated. The A1 mating type is mostly restricted to Europe $(37,60)$ and U.S. nurseries (29), while only the A2 mating type is found in North American forests $(43,60)$. However, the A2 mating type has been found in three isolates from Belgian nurseries $(70,74)$, one of which has since switched mating types from A2 to A1 (9). Expansion of the pathogen population is thought to be mostly via propagation of asexual clones $(26,43,69)$. Four evolutionary clonal lineages are currently known within $P$. ramorum: EU1, EU2, NA1, and NA2 $(32,43,67)$. NA1 and NA2 are restricted to North America, where the NA1 lineage is generally found in native forests and nurseries and NA2 isolates are mostly limited to nurseries. EU1 isolates are concentrated in Europe but have been found occasionally in U.S. nurseries $(33,37)$. EU2 is currently limited to Northern Ireland and Western Scotland (67). Lineages can be discriminated using gene sequences, amplified fragment length polymorphism, and simple sequence repeat markers $(26,43,44,59,71)$.

Corresponding author: M. Garbelotto; E-mail: matteog@ berkeley.edu

Accepted for publication 9 June 2014.

http://dx.doi.org/10.1094/PDIS-02-14-0151-RE

(C) 2014 The American Phytopathological Society
Several studies have examined the phenotypic differences between lineages in terms of traits such as spore and colony morphology $(7,43,75)$; colony growth rate $(7,75)$; spore production $(51,54,66,75)$; effect of fungicides $(20,40,58)$; and pathogenicity, aggressiveness, or host susceptibility $(7,15,20,36,39,40,51,66)$. Most have shown that there is substantial variability in phenotypic characteristics of individual isolates. However, assessments of the overall differences among lineages, if present, have been less consistent. The variety of growth media, inoculation techniques (agar versus zoospores, wounding versus nonwounding, and detached leaf versus sapling versus cut log), experimental temperatures, and isolates used in the disparate studies make it difficult to conclusively determine the existence and nature of phenotypic differences between lineages, or whether the differences seen are, in fact, an artifact of the isolates selected to represent each lineage. Finally, relationships and interactions among host susceptibility, temperature, and pathogen lineage have yet to be determined, reducing the power of predictive models.

The majority of host susceptibility studies have focused on either a single host and multiple temperatures (20) or multiple hosts at a single temperature, often using a single or relatively few isolates representative of each lineage $(1,15,51)$. Our objective was to conduct a more comprehensive study of the effect of lineage, temperature, and host on pathogenicity and host susceptibility.

The NA2 lineage has been historically confined to nurseries and has been shown in some studies to be more aggressive $(20,51)$. Providing more information on the virulence of NA2 and comparing it with NA1 is essential to determine whether its spread into native forests in North America would present an additional or different threat than that already posed by NA1. Indeed, a plant infected by an NA2 clone has recently been reported in California (23), as have some plants outside an infected nursery in Washington (10), highlighting the need for a better comparative assessment of virulence of these two lineages.

Our overall objective was to assess variability among populations of NA1 and NA2 populations. Host susceptibility was first 
assessed using detached-leaf assays performed on rhododendron and camellia, two ornamental species which are commonly infected in nurseries, with a variety of isolates from both the NA1 and NA2 lineages. Variability among isolates, between lineages, and between successive trials was also assessed in these studies. Next, zoospore inoculations of rhododendron and California bay laurel (Umbellularia californica or simply bay laurel), two species heavily involved in pathogen spread from nurseries to wild lands and within wild lands, were conducted at three different temperatures using mixtures of isolates from each lineage to investigate how lesion development and lesion area are affected by temperature and lineage in different hosts. To investigate differences among inoculation methods and among isolates within lineages, mycelial inoculations of bay laurel leaves were performed using the same six isolates and temperature regimes.

\section{Materials and Methods}

There were three different inoculation experiments conducted within this study. They are detailed in Table 1, and were conducted using the methods below.

Isolates. Cultures previously determined by morphology and sequence analysis to belong to the NA1 and NA2 lineages, respectively (43), were chosen at random from the Garbelotto Lab culture collection for detached-leaf trials (Table 2). In total, 15 NA1 predominantly from bay laurel in forests and 17 NA2 isolates predominantly from rhododendron in nurseries were used in inoculations (Table 2).

Culture preparation. To ensure viability and standardize culture age, isolates were taken out of long-term storage and passed through plant material as follows. Plugs of mycelium of isolates growing on clarified $10 \% \mathrm{~V} 8$ agar (72) were inoculated onto the abaxial surface of bay laurel leaves, and incubated in moist chambers at $18^{\circ} \mathrm{C}$ for 10 days to allow lesions to develop. The pathogen was reisolated from leaves by excising a small leaf section from the edge of the lesion and plating it onto PARP selective medium (pimaricin at $400 \mu \mathrm{l} / \mathrm{liter}$, ampicillin at $250 \mathrm{mg} / \mathrm{liter}$, rifampicin at $10 \mathrm{mg} / \mathrm{liter}$, and pentachloronitroenzene at $25 \mathrm{mg} / \mathrm{liter}$ ) (72). Colonies were identified as $P$. ramorum morphologically and subcultured onto $10 \%$ clarified V8 agar. Only cultures exhibiting uniform colony morphology were used for inoculations, to avoid the use of non-wild-type (NWT) isolates, known to have reduced virulence (46).

Zoospore inoculum preparation. Five agar plugs of each isolate, cut with a 4-mm-diameter cork borer, were evenly distributed around a $10 \%$ clarified V8 agar plate and grown in the dark at $18^{\circ} \mathrm{C}$ for 2 weeks. To induce production of sporangia in the resulting mycelia, the content of each plate was cut into pieces $1 \mathrm{~cm}^{2}$ in size and placed in two empty sterile petri plates. Agar pieces were flooded with $20 \mathrm{ml}$ of soil tea (dry soil at $10 \mathrm{~g} /$ liter, autoclaved for $30 \mathrm{~min}$ at $121 \mathrm{psi}$, then filtered with a sterile $0.2-\mu \mathrm{m}$ Nalgene filter), and incubated in the dark at $18^{\circ} \mathrm{C}$ for 2 days. The contents of the plates were transferred to acid-washed beakers, and zoospore release was induced by placing the beaker on ice for $30 \mathrm{~min}$, followed by incubation at room temperature for $1 \mathrm{~h}$. Zoospores were quantified using a hemocytometer and diluted to a final concentration of $5 \times 10^{4}$ zoospores $/ \mathrm{ml}$. For each experiment, sporangial growth and zoospore release were induced for all isolates at the same time from cultures of the same age.

For camellia and rhododendron single-temperature trials, the above procedure was done for each individual isolate. For the zoospore inoculation trials of bay laurel and rhododendron at multiple temperatures, a randomly selected subset of six isolates for each NA1 and NA2 group was used (Table 2). For the latter trial, sporangia from isolates belonging to the same lineage were combined to produce a lineage inoculum containing a mixture of all six isolates to try to assess a generalized response of the lineage rather than an isolate response. The subset was selected at random in order to represent the range of variation in the lineage, without bias.

Leaf randomization and incubation. Leaves were labeled and placed in trays according to a randomized complete block design to ensure even distribution of leaves and lineages between trays. Trays were lined with an absorbent mat with $500 \mathrm{ml}$ of distilled (d) $\mathrm{H}_{2} \mathrm{O}$ water in the base and overlaid with a grid support for the leaves. Trays were misted 10 times with $\mathrm{dH}_{2} \mathrm{O}$, then closed with an upturned tray used as a lid, sealed in autoclave bags, and placed into growth cabinets at the desired experiment temperature (Table 1) for $24 \mathrm{~h}$ before inoculations were performed. After inoculation, trays were misted with $\mathrm{dH}_{2} \mathrm{O}$ every 2 to 3 days. Total incubation time was 10 days for all experiments.

Table 1. Summary of inoculation experiments and their conditions ${ }^{\mathrm{a}}$

\begin{tabular}{|c|c|c|c|c|c|c|c|c|c|}
\hline \multirow[b]{2}{*}{ Experiment, inoculum, $T\left({ }^{\circ} \mathrm{C}\right)$} & \multirow[b]{2}{*}{ Species } & \multirow[b]{2}{*}{ Lineage } & \multirow[b]{2}{*}{$N$} & \multicolumn{2}{|c|}{ Leaves } & \multicolumn{2}{|l|}{ Lesion assessment } & \multirow[b]{2}{*}{ Trials } & \multirow[b]{2}{*}{ Analysis } \\
\hline & & & & Per treatment & Total & Measure & dpi & & \\
\hline \multicolumn{10}{|l|}{ Single temperature } \\
\hline \multicolumn{10}{|l|}{ Zoospore } \\
\hline \multirow[t]{7}{*}{20} & Camellia & NA1 & 13 & 16/isolate & 208 & Area, presence/absence & 10 & 2 & $\begin{array}{l}\text { ANOVA, } \\
\log \end{array}$ \\
\hline & & NA2 & 15 & 16/isolate & 240 & & & & \\
\hline & & Control & Soil tea & 16 & 16 & & & & \\
\hline & Rhododendron & NA1 & 13 & 16/isolate & 208 & & & & \\
\hline & & NA2 & 15 & 16/isolate & 240 & & & & \\
\hline & & Control & Soil tea & 16 & 16 & & & & \\
\hline & & & & Total & 928 & & & & \\
\hline \multicolumn{10}{|l|}{ Multiple temperatures } \\
\hline \multicolumn{10}{|l|}{ Zoospore mix } \\
\hline 12 & Rhododendron & NA1 & 6 mixed & 10/tree/temp & 150 & Area, presence/absence & 10 & 2 & $\begin{array}{l}\text { ANOVA, } \\
\log \end{array}$ \\
\hline 20 & & NA2 & 6 mixed & 10/tree/temp & 150 & & & & \\
\hline \multirow[t]{5}{*}{$24 / 15$} & & Control & Soil tea & $1 /$ tree/temp & 15 & & & & \\
\hline & Bay laurel & NA1 & 6 mixed & 10/tree/temp & 150 & & & & \\
\hline & & NA2 & 6 mixed & 10/tree/temp & 150 & & & & \\
\hline & & Control & Soil tea & $1 /$ tree/temp & 15 & & & & \\
\hline & \multicolumn{4}{|c|}{ Mycelium } & & & & & \\
\hline 12 & Bay laurel & NA1 & 6 & 10/tree/temp & 150 & Presence/absence & 10 & 2 & GLMM \\
\hline 20 & & NA2 & 6 & 10/tree/temp & 150 & & & & \\
\hline \multirow[t]{2}{*}{$24 / 15$} & & Control & V8 Agar & $1 /$ tree/temp & 15 & & & & \\
\hline & & & & Total & 315 & & & & \\
\hline
\end{tabular}

\footnotetext{
a Abbreviations: $T=$ temperature, $N=$ number of isolates, $\mathrm{dpi}=$ days postinoculation, ANOVA $=$ analysis of variance, $\log =\operatorname{logistic}$ regression, and GLMM $=$ generalized linear mixed model.
} 
Zoospore inoculation. A 40- $\mu$ l drop of zoospore suspension was placed on the abaxial surface of each leaf. Control leaves were inoculated with $40 \mu \mathrm{l}$ of $\mathrm{dH}_{2} \mathrm{O}$. All inoculations were performed using acid-washed pipette tips and tubes within the growth chambers to avoid subjecting leaves to temperature fluctuations.

Mycelial inoculation. Plugs of agar, $3 \mathrm{~mm}$ in diameter, were cut aseptically from the growing edge of 2-week-old cultures of each isolate of $P$. ramorum growing on $10 \%$ clarified V8 agar (15 $\mathrm{ml}$ of agar per plate). Control plugs of identical size were cut from a clean $10 \%$ clarified V8 agar plate. Plugs were placed mycelium-down onto the abaxial surface of leaves, surface cleaned with $70 \%$ (vol/vol) ethanol. Plugs were equally spaced with three plugs on either side of the midvein; six plugs were added to each leaf (Fig. 1). Control leaves were inoculated with six plugs of $10 \%$ clarified V8 agar. Inoculations were performed within the growth chambers to avoid subjecting leaves to temperature changes.

Single-temperature zoospore inoculation of rhododendron and camellia. Sixteen leaves of both Rhododendron catawbiense 'Boursault' and Camellia setsugekka were inoculated with zoospore suspensions of 13 different NA1 isolates and 15 NA2 isolates (Tables 1 and 2). Sixteen control leaves of each host plant were inoculated with $\mathrm{dH}_{2} \mathrm{O}$. Leaves were incubated in moist tray chambers, as described above, at $20^{\circ} \mathrm{C}$ for 10 days.

Multiple-temperature inoculation of rhododendron and bay laurel. Eleven leaves were plucked from five bay laurel (U1 to U5) and 'Cunningham's White' rhododendron (R1 to R5) plants, $24 \mathrm{~h}$ prior to inoculation, for each of the three temperature treatments: (i) $12^{\circ} \mathrm{C}$, (ii) $20^{\circ} \mathrm{C}$, and (iii) $24^{\circ} \mathrm{C}$ during the day $\left(10 \mathrm{~h}\right.$ ) and $15^{\circ} \mathrm{C}$ at night, mimicking the temperature fluctuations in late spring in coastal California. For each temperature, and each tree, 10 leaves were inoculated with NA1 or NA2 inocula (either zoospores or agar plugs) while 1 leaf was used as a control for a total of 105 leaves per temperature per species and 63 leaves from each plant (21 per temperature). In all experiments, leaves were picked from the middle of branches, avoiding the first leaves and any that were not fully mature as well as the oldest leaves.

The six isolates used for multiple-temperature zoospore inoculations were also used for agar inoculations of detached leaves (Table 2). Two separate trials were conducted, with identical setups, beginning with the isolates obtained from reisolation after passing through bay laurel.

Leaf assessment. After 10 days of incubation, leaves were removed from the trays and surface sterilized with $70 \%$ ( $\mathrm{vol} / \mathrm{vol})$ ethanol to remove any residual agar or zoospore inoculum from the leaf surface. Leaves were scanned using an Epson Perfection 1650 scanner and lesion presence and size were analyzed using Assess (v. 1.0; American Phytopathological Society, St Paul, MN). Both total leaf area (in square centimeters), and lesion area (in square centimeters) were calculated.

For leaves inoculated with zoospores, reisolations were performed from all asymptomatic leaves in the region of the inocula-

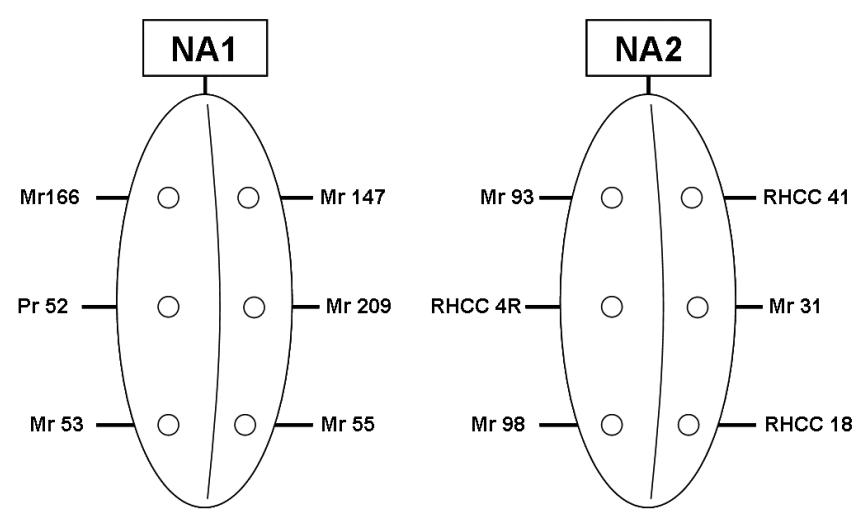

Fig. 1. Locations of agar plug and isolates in mycelial inoculations of bay laurel.

Table 2. Phytophthora ramorum isolates used in inoculation experiments

\begin{tabular}{|c|c|c|c|c|c|c|}
\hline Isolate code & Isolation year & Country & County, State & Host isolated from & Lineage & Experiment $^{\mathrm{a}}$ \\
\hline A 2 & 2005 & United States & Marin, CA & Notholithocarpus densiflora & NA1 & $\dagger$ \\
\hline A 28 & 2005 & United States & Marin, CA & Umbellularia californica & NA1 & $\dagger$ \\
\hline A 29 & 2005 & United States & Marin, CA & U. californica & NA1 & $\dagger$ \\
\hline BC 27 & 2005 & United States & Santa Cruz, CA & U. californica & NA1 & $\dagger$ \\
\hline BC 8 & 2005 & United States & Santa Cruz, CA & U. californica & NA1 & $\dagger *$ \\
\hline BO 18 & 2005 & United States & Marin, CA & U. californica & NA1 & $\dagger$ \\
\hline BO 28 & 2005 & United States & Marin, CA & U. californica & NA1 & $\dagger$ \\
\hline CH 14 & 2005 & United States & Marin, CA & U. californica & NA1 & $\dagger *$ \\
\hline $\mathrm{CH} 25$ & 2005 & United States & Marin, CA & U. californica & NA1 & $\dagger$ \\
\hline DG 1 & 2005 & United States & Marin, CA & U. californica & NA1 & $\dagger$ \\
\hline DG 7 & 2005 & United States & Marin, CA & $U$. californica & NA1 & $\dagger *$ \\
\hline $\operatorname{Mr} 53$ & 2004 & United States & Pennsylvania & Camellia (bonsai) & NA1 & * \\
\hline $\operatorname{Mr} 55$ & 2004 & United States & & & NA1 & * \\
\hline Pr 102 & & United States & Marin, CA & Quercus agrifolia & NA1 & $\dagger$ \\
\hline $\operatorname{Pr} 52$ & 2006 & United States & Santa Cruz, CA & Rhododendron & NA1 & $\dagger *$ \\
\hline MEP 1570 & 2004 & United States & $\ldots$ & & NA2 & $\dagger$ \\
\hline Mr 98 & 2005 & United States & Sacramento, CA & Rhododendron sp. var. 'Colonel Coen' & NA2 & * \\
\hline Mr 106 & 2005 & United States & Sacramento, CA & Camellia 'Emperor of Russia' & NA2 & $\dagger$ \\
\hline $\operatorname{Mr} 31$ & 2004 & United States & Washington State & Rhododendron sp. var. Capistrano & NA2 & $\dagger *$ \\
\hline RHCC 1 & 2005 & United States & Sacramento, CA & Rhododendron sp. var. 'Colonel Coen' & NA2 & $\dagger$ \\
\hline RHCC 13 & 2005 & United States & Sacramento, CA & Rhododendron sp. var. 'Colonel Coen' & NA2 & $\dagger$ \\
\hline RHCC 18 & 2005 & United States & Sacramento, CA & Rhododendron sp. var. 'Colonel Coen' & NA2 & $\dagger *$ \\
\hline RHCC 26R & 2005 & United States & Sacramento, CA & Rhododendron sp. var. 'Colonel Coen' & NA2 & $\dagger$ \\
\hline RHCC 31 & 2005 & United States & Sacramento, CA & Rhododendron sp. var. 'Colonel Coen' & NA2 & $\dagger$ \\
\hline RHCC 32 & 2005 & United States & Sacramento, CA & Rhododendron sp. var. 'Colonel Coen' & NA2 & $\dagger$ \\
\hline RHCC 35R & 2005 & United States & Sacramento, CA & Rhododendron sp. var. 'Colonel Coen' & NA2 & $\dagger *$ \\
\hline RHCC 38 & 2005 & United States & Sacramento, CA & Rhododendron sp. var. 'Colonel Coen' & NA2 & $\dagger$ \\
\hline RHCC 38R & 2005 & United States & Sacramento, CA & Rhododendron sp. var. 'Colonel Coen' & NA2 & $\dagger$ \\
\hline RHCC 41 & 2005 & United States & Sacramento, CA & Rhododendron sp. var. 'Colonel Coen' & NA2 & $\dagger *$ \\
\hline RHCC 42 & 2005 & United States & Sacramento, CA & Rhododendron sp. var. 'Colonel Coen' & NA2 & $\dagger$ \\
\hline RHCC 4R & 2005 & United States & Sacramento, CA & Rhododendron sp. var. 'Colonel Coen' & NA2 & $\dagger *$ \\
\hline RHCC 7R & 2005 & United States & Sacramento, CA & Rhododendron sp. var. 'Colonel Coen' & NA2 & $\dagger$ \\
\hline
\end{tabular}

a $\dagger$ Camellia and rhododendron zoospore inoculations at single temperature. * Rhododendron and bay laurel zoospore and agar inoculations at multiple temperatures. 
tion point. A selection of NA1- and NA2-inoculated leaves which had visible lesions were also reisolated to confirm presence of the pathogen. Isolations were made from the center of the lesion, the edge, and approximately $5 \mathrm{~mm}$ from the edge and plated onto PARP selective medium.

Data analysis. Unless otherwise stated, analyses were performed in JMP (v. 10.0.0; SAS Institute). Data were natural $\log$ transformed and, to account for zero values, the mean lesion area was added to each value before transformation. Data resulting from single-temperature zoospore inoculation of rhododendron and camellia were analyzed by analysis of variance (ANOVA). The dependent variable was lesion area, modeled with a fixed effect of lineage and random effects of isolate nested in lineage, inoculation date, and block nested within inoculation date. Standard least squares and restricted maximum likelihood model fitting were used. Differences in the transformed lesion area between lineages at different temperatures were compared by ANOVA, with each host species modeled separately; isolate within lineage as a random effect; and temperature, lineage, and the temperature-lineage interaction as fixed effects. Leaf area and greenhouse tray (within temperature) were initially included in the model but neither had a significant effect; therefore, they were ultimately excluded. Where variances between trials were homogenous, the inoculation date was included as an effect in the model to compare the two trials. For zoospore inoculations, lesion presence or absence was modeled using logistic regressions, with the dependent variable of lesion presence and fixed effects of lineage, inoculation date, and the inoculation date-lineage interaction. After agar inoculations of bay laurel leaves, leaves were scanned and images were visually inspected to determine the presence or absence of a lesion at each of the six inoculation points per leaf. Lesion area was not measured for this inoculation method, due to limited lesion development and poorly defined lesion margins. Lesion presence or absence for agar inoculations at different temperatures was modeled using a generalized linear mixed model (GLMM), with the dependent variable lesion presence and fixed effects of temperature, lineage, and the temperature-lineage interaction. Isolate within lineage and tree from which leaves were taken were included as random effects. GLMM analyses were performed using the package lme4 (3) in R (61).

\section{Results}

Single-temperature zoospore inoculation of rhododendron and camellia. Camellia. There was high variability in lesion sizes produced on camellia among isolates, with a general trend toward larger lesions produced by NA1 isolates (mean range: trial 1, 0.03 to $3.71 \mathrm{~cm}^{2}$; trial $2,0.05$ to $3.45 \mathrm{~cm}^{2}$ ) than NA2 isolates (mean range: trial $1,0.13$ to $1.43 \mathrm{~cm}^{2}$; trial $2,0.08$ to $0.78 \mathrm{~cm}^{2}$ ) (Fig. 2). Lesions were smaller overall in the second trial but NA1 lesions were still significantly larger than NA2 lesions (Fig. 3B). When leaves were scored solely for presence or absence of lesions, there were more lesions present on NA1-inoculated leaves than those inoculated with NA2 in trial 1; however, the opposite was found in trial 2 (Fig. 3A). The numbers of NA1 lesions present were not significantly different between trials but there were significantly more NA2 lesions in the second trial compared with the first. When presence or absence data were modeled with a logistic regression, all effects were significant $(P<0.05)$ (Table 3$)$. ANOVA performed on the transformed lesion area showed that there was a significant effect of lineage $(F=34.613, P<0.0001)$ (Table 4$)$ and
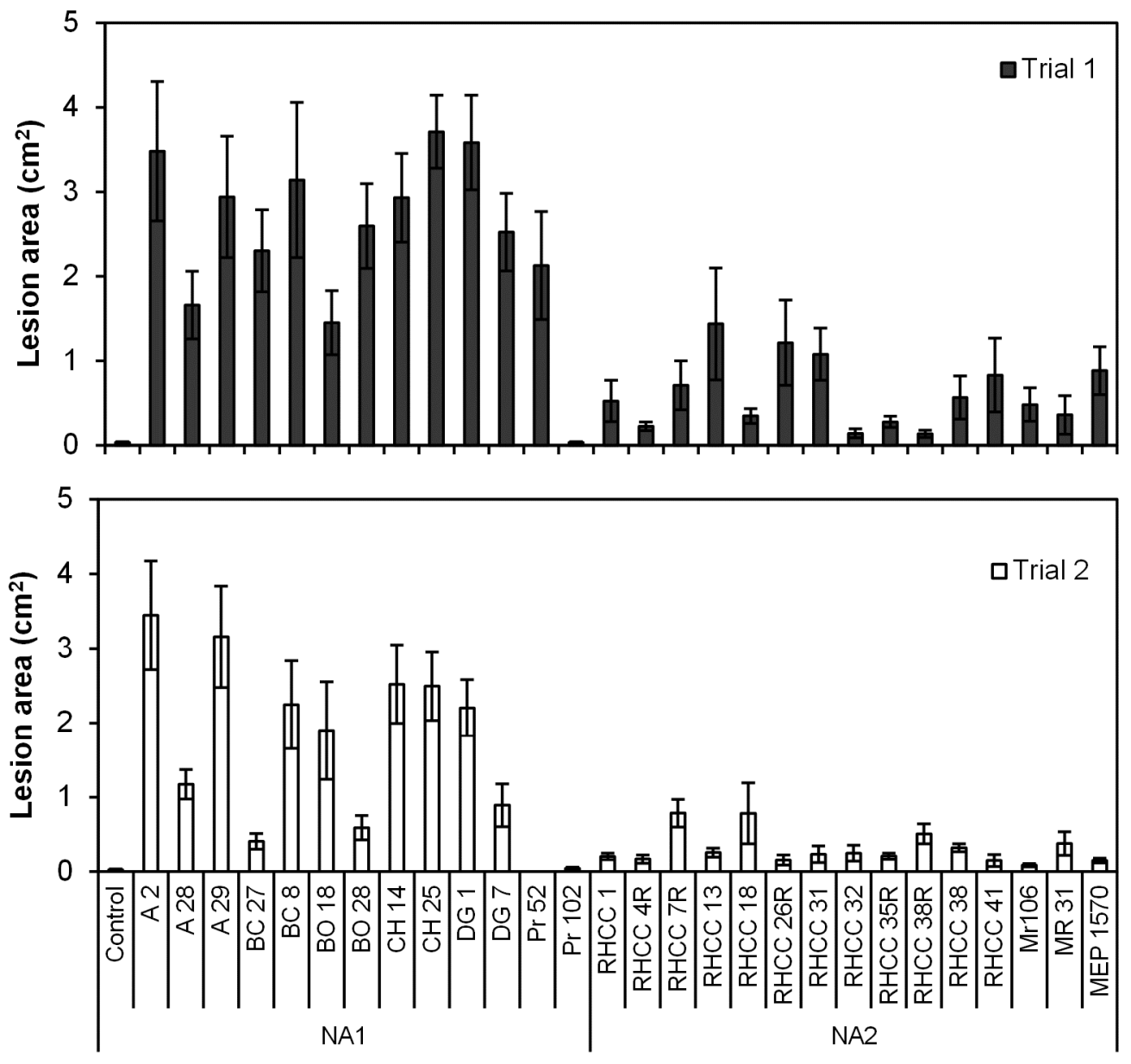

Isolate within lineage

Fig. 2. Lesion area (in square centimeters) of isolates from NA1 and NA2 lineages tested on Camellia setsugekka in two separate trials. Error bars are \pm standard error of the mean. 
that the random effects of inoculation date and isolate within lineage contributed to a large amount of the variation in the data ( 36.540 and $15.252 \%$, respectively; Table 4).

Rhododendron. Lesion size was highly variable among isolates inoculated onto rhododendron leaves (Fig. 4). There were significantly more lesions on leaves inoculated with NA2 zoospores than on those inoculated with NA1 zoospores in trial 1 but, in trial 2, there was no significant difference between lineages (Fig. 5A). Lineage, isolate within lineage, and inoculation date were all significant when lesion presence or absence data were modeled with a logistic regression (Table 5). The interaction of inoculation datelineage was not significant.

ANOVA of transformed lesion area found that lineage was not significant $(F=2.54, P=0.1208)$ and that the random effects of isolate within lineage and inoculation date contributed a large percentage of the variation in the data $(15.387$ and $5.796 \%$, respectively; Table 6; Fig. 5B).

Results for the two trials were very similar for NA1 isolates but, for NA2, lesions were generally smaller in the second trial than in the first, with a few exceptions. For NA1, mean range in trial 1 was 0.14 to $3.96 \mathrm{~cm}^{2}$ and in trial 2 was 0.02 to $3.29 \mathrm{~cm}^{2}$; for NA2, mean range in trial 1 was 0.42 to $5.10 \mathrm{~cm}^{2}$ and in trial 2 was 0.31 to $2.44 \mathrm{~cm}^{2}$ (Fig. 4). Control lesions were very small, averaging $0.02 \pm 0.004 \mathrm{~cm}^{2}$.

Table 3. Logistic regression results for lesion presence or absence for single-temperature camellia detached-leaf zoospore inoculation

\begin{tabular}{lrrr}
\hline Test, source & DF & L-R $\chi^{\mathbf{2}}$ & Prob $>\chi^{\mathbf{2}}$ \\
\hline Lesion presence & & & \\
Lineage & 1 & 21.200 & $<0.0001^{*}$ \\
Isolate (Lineage) & 26 & 194.549 & $<0.0001^{*}$ \\
Inoculation date (InocDate) & 1 & 4.334 & $0.0374^{*}$ \\
InocDate $\times$ Lineage & 1 & 17.318 & $<0.0001^{*}$ \\
\hline
\end{tabular}

A

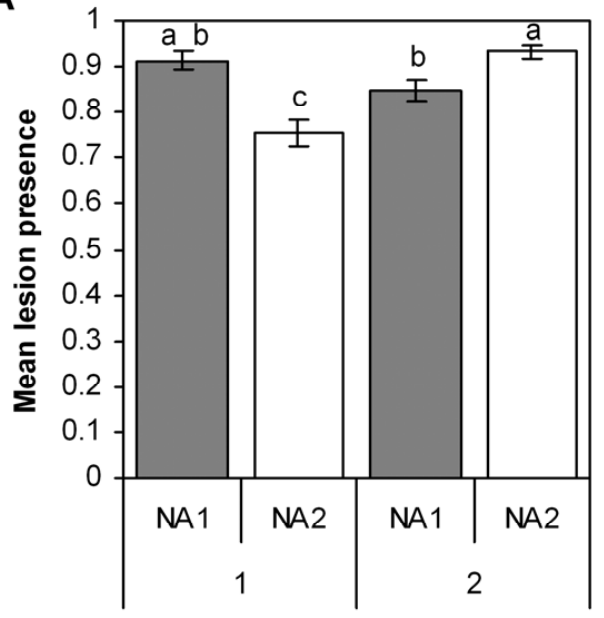

Lineage within trial
Multiple-temperature inoculations of rhododendron and bay laurel. Zoospore inoculations. In bay laurel (Fig. 6A), at both 12 and $20^{\circ} \mathrm{C}$, there was a trend toward larger mean lesion area in NA2 than NA1 $\left(12^{\circ} \mathrm{C}\right.$ : NA1 mean $=2.20 \mathrm{~cm}^{2}$ and NA2 mean $=2.41$ $\mathrm{cm}^{2} ; 20^{\circ} \mathrm{C}$ : NA1 mean $=1.86 \mathrm{~cm}^{2}$ and NA2 mean $=3.62 \mathrm{~cm}^{2}$ ) but, at $24^{\circ} \mathrm{C}$, this was reversed, with NA1 lesions larger than NA2 (NA1 mean $=1.54 \mathrm{~cm}^{2}$ and NA2 mean $=1.13 \mathrm{~cm}^{2}$ ), although these differences were not statistically significant. In rhododendron (Fig. 6B) inoculated at $12^{\circ} \mathrm{C}$, NA1 and NA2 lesions were generally small $\left(\mathrm{NA} 1\right.$ mean $=1.42 \mathrm{~cm}^{2}$ and NA2 mean $=1.21 \mathrm{~cm}^{2}$ ) and there was no significant difference between lineages. At $20^{\circ} \mathrm{C}$, lesions were larger on average than at any of the other experimental temperatures $\left(\mathrm{NA} 1\right.$ mean $=11.45 \mathrm{~cm}^{2}$ and NA2 mean $=20.02 \mathrm{~cm}^{2}$ ), and NA 2 lesions were significantly larger than NA1 $(P<0.05$ by Tukey's honestly significant difference). The same trend (i.e., NA2 lesions larger than NA1) was observed at 24 and $15^{\circ} \mathrm{C}$ (NA1 mean $=7.24 \mathrm{~cm}^{2}$ and NA2 mean $=10.14 \mathrm{~cm}^{2}$ ) although, at this temperature regime, difference between lineages was not significant. Lesions at $24^{\circ} \mathrm{C}$ were overall smaller, on average, than those at $20^{\circ} \mathrm{C}$. Data for both trials showed the same patterns. Only data for trial 1 is presented in Figure 6 but trial 2 had the same pattern and statistical significance between groups.

ANOVA showed that overall temperature had a significant effect on lesion area in both species (bay laurel: $P=0.0001$; rhododendron: $P<0.0001$; Table 7) but response varied with host species. In bay laurel, lesions were significantly smaller when incubated at 24 and $15^{\circ} \mathrm{C}$ compared with results obtained at either the 12 or $20^{\circ} \mathrm{C}$ incubation. Rhododendron lesions, instead, were smallest at $12^{\circ} \mathrm{C}$ but indistinguishable between $20^{\circ} \mathrm{C}$ and 24 or $15^{\circ} \mathrm{C}$ (Fig. 6).

Pathogen lineage on its own had no significant effect $(P=0.94)$. However, there was a marginally significant effect of the temperature-lineage interaction $(P=0.08)$ in both host species (Table 7). NA2 zoospores caused larger lesions than NA1 on both bay laurel and rhododendron leaves at $20^{\circ} \mathrm{C}$ but the difference was significant
B

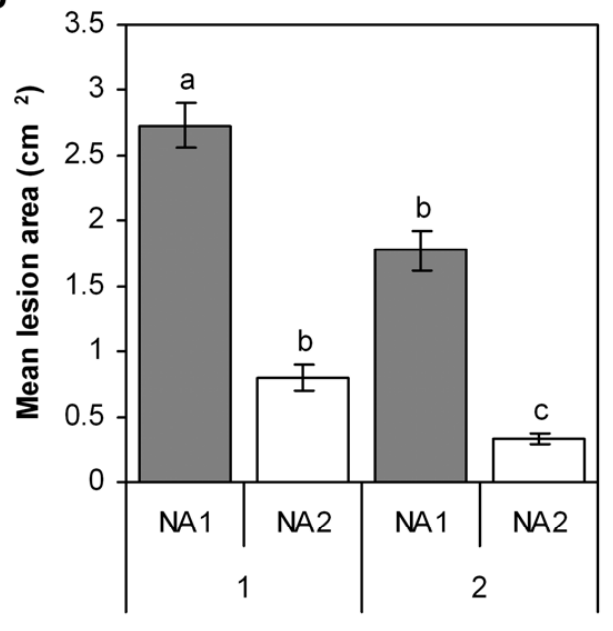

Lineage within trial

Fig. 3. Camellia detached-leaf zoospore inoculation assay testing lineages NA1 and NA2 in two trials (1 and 2). A, Frequency of lesion presence and B, mean lesion area (in square centimeters). Error bars are \pm standard error of the mean. Different letters above bars in each plot indicate statistical difference (Tukey-Kramer honestly significant difference, $P<0.05)$.

Table 4. Analysis of variance results for lesion area for single-temperature camellia detached-leaf zoospore inoculation

\begin{tabular}{llccccccc}
\hline Test, effect & \multicolumn{1}{c}{ Source } & DF & DF Den & $\boldsymbol{F}$ ratio & Prob $>\boldsymbol{F}$ & Var ratio & Var component & Percent of total \\
\hline Lesion area & & & & & & & & \\
$\quad$ Fixed & Lineage & 1 & 26.52 & 34.613 & $<0.0001^{*}$ & $\ldots$ & $\ldots$ \\
Random & Isolate (Lineage) & $\ldots$ & $\ldots$ & $\ldots$ & $\ldots$ & 0.328 & 0.059 & 15.252 \\
& Inoculation date (InocDate) & $\ldots$ & $\ldots$ & $\ldots$ & $\ldots$ & 0.785 & 0.141 & 36.54 \\
& Block (InocDate) & $\ldots$ & $\ldots$ & $\ldots$ & $\ldots$ & 0.036 & 0.006 & 1.664 \\
& Residual & $\ldots$ & $\ldots$ & $\ldots$ & $\ldots$ & $\ldots$ & 0.18 \\
& Total & $\ldots$ & $\ldots$ & $\ldots$ & $\ldots$ & $\ldots$ & 0.386 \\
\hline
\end{tabular}


only in rhododendron. Otherwise, there were no significant differences between lineages within temperatures.

Agar inoculations of bay laurel. Agar inoculations of unwounded bay laurel leaves at three temperatures $(12,20$, or 24 and $15^{\circ} \mathrm{C}$ ) were scored for the presence or absence of lesions at the six inoculation points per leaf. The mean number of lesions present on leaves was between 2.0 and 3.0 at both 12 and $20^{\circ} \mathrm{C}$ and between 1.5 and 2.20 at $24^{\circ} \mathrm{C}$ (Fig. 7). There was a significant effect of
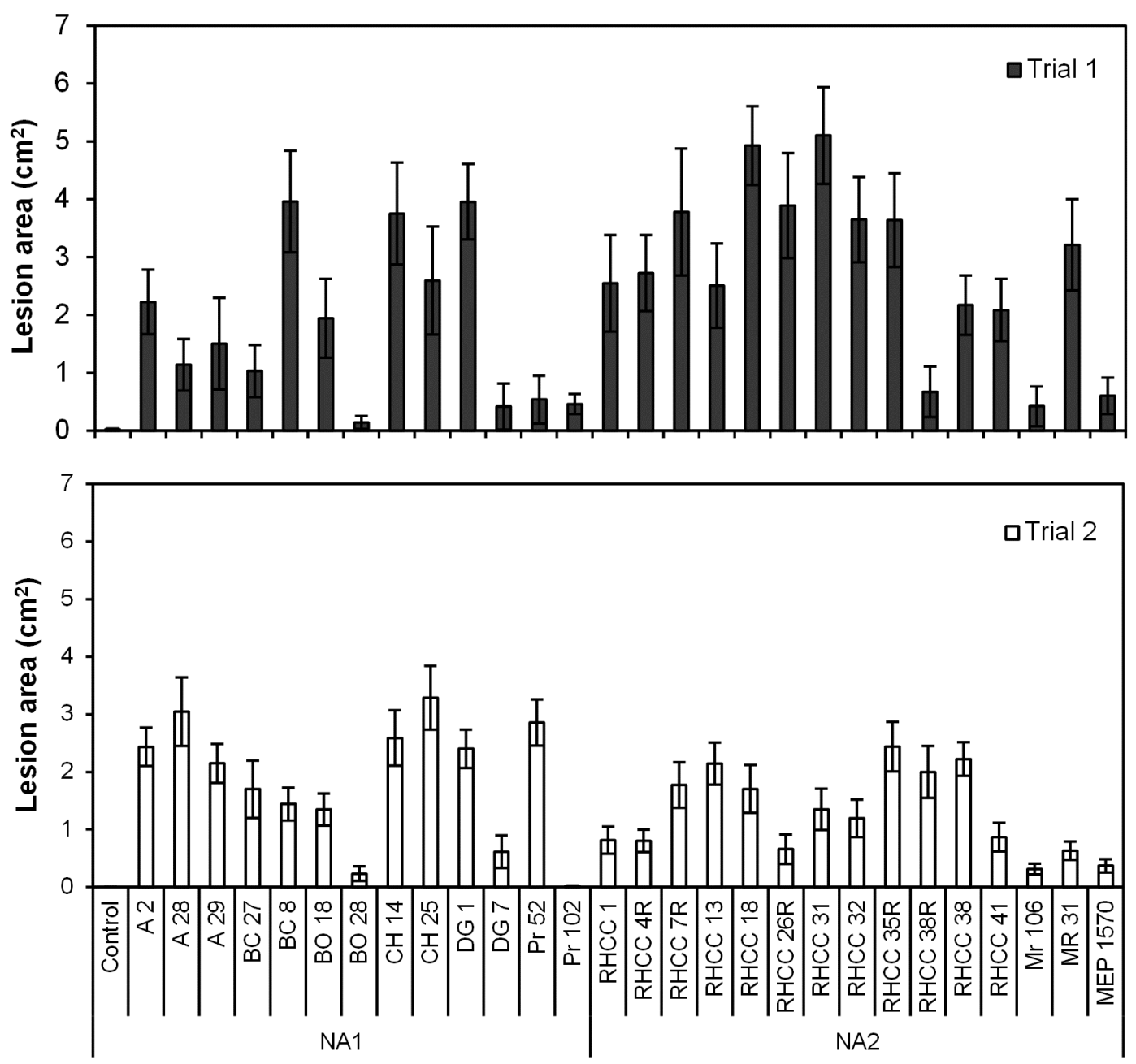

Isolate within lineage

Fig. 4. Lesion area (in square centimeters) of isolates from NA1 and NA2 lineages tested on Rhododendron catawbiense 'Boursault' in two trials. Error bars are \pm standard error of the mean.

A

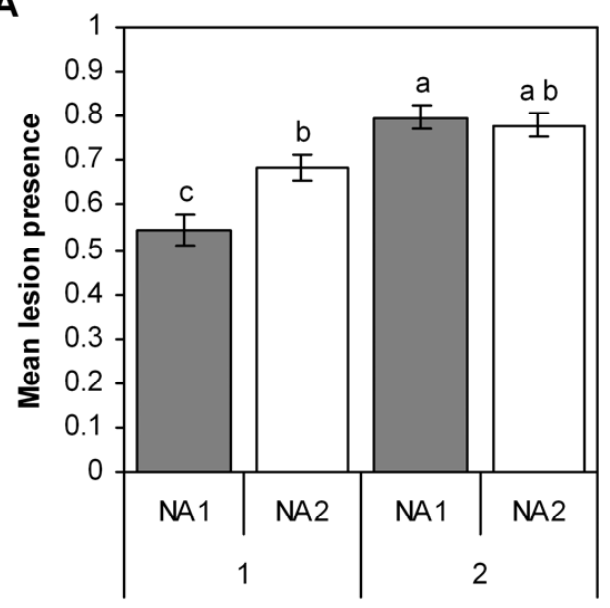

Lineage within trial
B

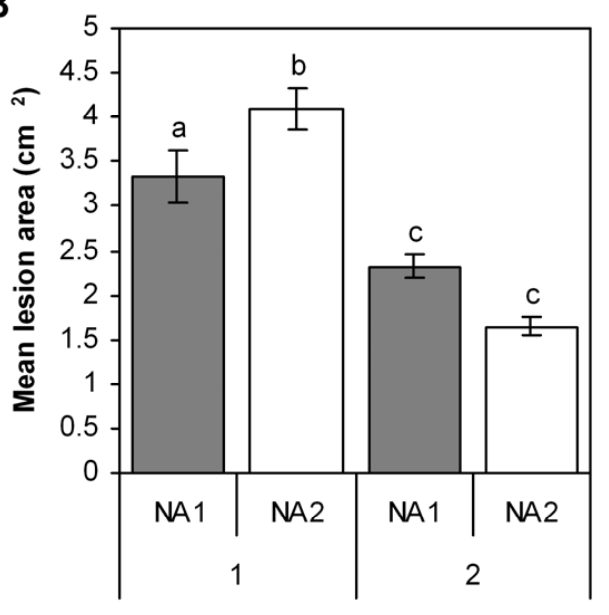

Lineage within trial

Fig. 5. Rhododendron detached-leaf inoculation with zoospores, testing lineages NA1 and NA2 in two trials (1 and 2). A, Lesion presence and B, lesion area (in square centimeters). Error bars are \pm standard error of the mean. Different letters above bars in each plot indicate statistical difference (Tukey-Kramer honestly significant difference, $P<0.05)$. 
temperature $(P=0.00018$; Table 8$)$. Bay laurel leaves incubated at 24 and $15^{\circ} \mathrm{C}$ had significantly fewer visible lesions than those at the other temperatures. There were no other significant effects overall, although NA2 isolates trended toward having more visible lesions than NA1 at all temperatures. Furthermore, there were significantly more NA2 lesions at 12 or $20^{\circ} \mathrm{C}$ than NA1 lesions at 24 and $15^{\circ} \mathrm{C}$ (Fig. 7).

\section{Discussion}

P. ramorum is an emergent generalist pathogen $(31,39)$ and has been found to be capable of infecting a large number of hosts $(2,12,24,36,65)$. Consequently, strict plant movement restrictions are imposed in the areas where the disease is present. In North America, this is with the aim of limiting the spread of the forest populations of the pathogen and to prevent outbreaks of lineages such as NA2 and EU1 which, until recently, have not been reported from plants outside nurseries in California (10). The recent finding of an NA2 isolate on an infected plant in California (23) is a compelling reason to comprehensively assess differences in aggressiveness between the two clonal lineages.

There have been a number of published trials aimed at testing pathogen aggressiveness and host susceptibility and at comparing a variety of other phenotypic traits between clonal lineages and isolates $(1,7,15,20,35,36,40,41,51,54,58,64,65)$. However, these individual trials have not included a representative population of

Table 5. Logistic regression results for lesion presence or absence for single-temperature rhododendron detached-leaf zoospore inoculation

\begin{tabular}{lrrc}
\hline Test, source & DF & L-R $\chi^{\mathbf{2}}$ & Prob $>\chi^{\mathbf{2}}$ \\
\hline Lesion presence & & & \\
Lineage & 1 & 4.544 & $0.0330^{*}$ \\
Isolate (Lineage) & 26 & 124.081 & $<0.0001^{*}$ \\
Inoculation date (InocDate) & 2 & 34.711 & $<0.0001^{*}$ \\
InocDate $\times$ Lineage & 1 & 0.545 & 0.4606 \\
\hline
\end{tabular}

isolates or a range of hosts and temperatures simultaneously. In this study, we examined the differences between the North American lineages NA1 and NA2 on rhododendron, bay laurel, and camellia at different temperatures, using a larger number of isolates and replications. Zoospore and mycelial inoculations were performed without wounding in order to allow an assessment of the ability of the pathogen to survive on and infect the host, which may have more relevance when trying to model the factors affecting the risk of infection spread in natural ecosystems and nurseries. Some studies have shown that zoospore inoculations do not always produce significant infection (14) but we did not find this to be the case, and deem the ability of the pathogen to infect host tissue in the absence of a wound an important phenotypic trait for measuring pathogenicity. After initial infection, P. ramorum progresses to a necrotrophic phase, inducing the necrotic lesions necessary for sporulation and, thus, transmission. Such hemibiotrophic pathogens have been shown to mobilize host defenses for this purpose $(45,48)$; indeed, the production of elicitins has been demonstrated to play a strong role in $P$. ramorum aggressiveness $(50,51)$. Because lesions play a critical role in transmission, the presence and size of lesions is a valuable proxy for the severity of a particular host-pathogen interaction. For the host-temperaturelineage trials, we used a zoospore suspension comprising a mixture of inoculum from six randomly selected isolates. This was done with the objective of assessing a generalized response to each of the different lineages.

$P$. ramorum clonal lineages are thought to have arisen due to allopatric isolation in the native range of the pathogen $(11,26,43)$. One would expect interlineage differences to develop due to lack of recombination among isolated lineages. Variation may also be driven by selection and adaptation to local environmental conditions and interactions between host and pathogen. Other plant pathogens and Phytophthora spp. have shown differences in phenotype between clonal lineages in terms of growth rate, spore size, latent period, and aggressiveness $(6,17,78)$. Previous comparative studies

Table 6. Analysis of variance results for lesion area for single-temperature rhododendron detached-leaf zoospore inoculation

\begin{tabular}{|c|c|c|c|c|c|c|c|c|}
\hline Test, effect & Source & DF & DF Den & $F$ ratio & Prob $>F$ & Var ratio & Var component & Percent of total \\
\hline \multicolumn{9}{|l|}{ Lesion area } \\
\hline Fixed & Lineage & 1 & 30.57 & 2.5474 & 0.1208 & & & \\
\hline \multirow{5}{*}{ Random } & Isolate (Lineage) & $\ldots$ & $\ldots$ & $\ldots$ & $\ldots$ & 0.196 & 0.049 & 15.387 \\
\hline & Inoculation date (InocDate) & $\ldots$ & $\ldots$ & $\ldots$ & $\ldots$ & 0.074 & 0.019 & 5.796 \\
\hline & Block (InocDate) & $\ldots$ & $\ldots$ & $\ldots$ & $\ldots$ & 0.005 & 0.001 & 0.430 \\
\hline & Residual & $\ldots$ & $\ldots$ & $\ldots$ & $\ldots$ & $\ldots$ & 0.250 & 78.387 \\
\hline & Total & $\ldots$ & $\ldots$ & $\ldots$ & $\ldots$ & $\ldots$ & 0.319 & 100.000 \\
\hline
\end{tabular}

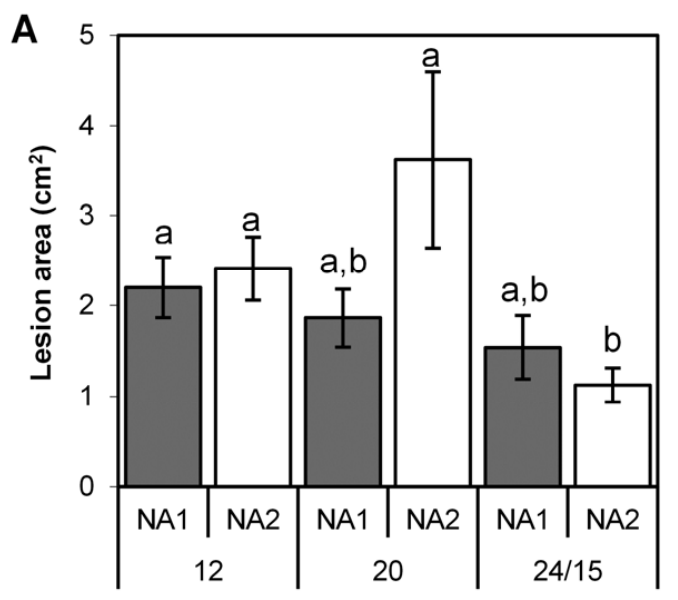

Lineage within temperature

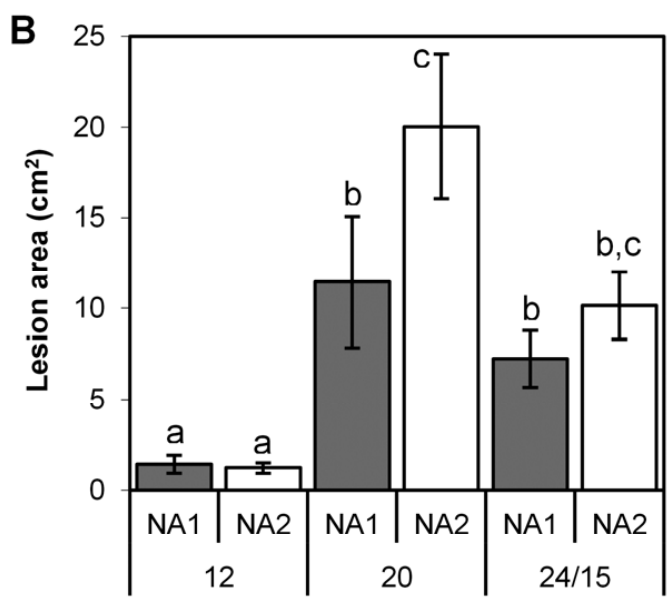

Lineage within temperature

Fig. 6. Mean lesion area (in square centimeters) caused by zoospore suspensions of Phytophthora ramorum lineages NA1 and NA2 under three incubation conditions on leaves of A, bay laurel and B, 'Cunningham's White' rhododendron. Bars marked with different letters are significantly different at $P<0.05$ by Tukey-Kramer's honestly significant difference. Error bars are \pm standard error of the mean. 
have shown NA2 and EU1 to behave very similarly, while other studies reported that NA2 isolates were more aggressive than NA1 $(7,20,51)$. Although the clonal lineages appear to differ in their epidemiological attributes, these studies used a limited set of parameters, and results were not necessarily sufficiently consistent to use the traits as predictors of lineage. Our results show that, with an appropriate representation of isolates, the outcome may vary depending on host. In camellia, NA1 was more aggressive than NA2, demonstrating a strong host-lineage interaction. This interaction may explain differences in spread rates when outbreaks are driven by different hosts, as in the case in Oregon (major infectious host is tanoak), California (major infectious host is California bay laurel), and the United Kingdom (major infectious host is larch). Our results are in contrast to the work of Elliot et al. (20), in which NA2 isolates were found to be more aggressive than NA1 on almost all the host species tested, including camellia (with the exception of Vitis spp.). This discrepancy could be due to the smaller number of isolates used by Elliot et al. (20) and highlights that, whereas susceptibility of a host species can be tested using one or a few isolates, comparative analyses aimed at understanding variability among pathogen (and host) individuals require a larger and appropriate representation of isolates.

Variable susceptibility to $P$. ramorum has been observed within four major, relatively intensively studied hosts: rhododendron, tanoak, California bay laurel, and coast live oak $(14,18,38,41)$. However, these studies used only one or two isolates. We found that there was high variability between the isolates that we used to inoculate rhododendron, some of which proved to be far more pathogenic than $\operatorname{Pr} 52$ or Pr102, two of the standard isolates used in previous inoculation studies. Given the amount of variability among isolates found in this and other studies, the vulnerability of some host species, or at least the range or spectrum of such susceptibility, may have been underestimated. In our analyses, we did not find any appreciable differences in susceptibility among plants of the same species but it is important to keep in mind that the analysis of within-host species variability was not a major goal of this study and, consequently, the number of individual plants per species in our study was limited.

Mycelial inoculations of bay laurel leaves were performed to assess variability within lineages as well as among lineages across temperature regimes. Although the comparison is complicated by the different modes of infection, the results mirrored those obtained with zoospore inoculation but with less variability overall. This is as would be expected, considering that mycelial inoculations bypass the zoospore encystment and germination steps, whereas the pathogen is already established in the plugs used as inoculum for mycelial tests and has a reservoir of energy. Spores of foliar pathogens commonly use stomata entry points point for in-

Table 8. Single-term deletion details for generalized linear mixed model of infection success or lesion presence of mycelial plugs on bay laurel at three temperatures $^{\mathrm{a}}$

\begin{tabular}{lcccl}
\hline Variable & DF & AIC & LRT & Prob $>\boldsymbol{\chi}^{\mathbf{2}}$ \\
\hline Temperature & 2 & 1,185 & 17.29 & $0.00018^{*}$ \\
Lineage & 1 & 1,172 & 2.38 & 0.123 \\
Temperature $\times$ Lineage & 2 & 1,172 & 0.243 & 0.89 \\
\hline
\end{tabular}

a See text for model details.

Table 7. Analysis of variance of Lesion area $\left(\mathrm{cm}^{2}\right)$ caused by zoospore suspension inoculations of both bay laurel and Rhododendron at multiple temperatures $^{\mathrm{a}}$

\begin{tabular}{|c|c|c|c|c|c|}
\hline Test, effect & Source & DF & SS & $F$ ratio & Prob $>F$ \\
\hline \multicolumn{6}{|l|}{ Bay laurel } \\
\hline \multirow[t]{3}{*}{ Fixed } & Temperature & 2 & 4.118 & 9.385 & $0.0001 *$ \\
\hline & Lineage & 1 & 0.001 & 0.006 & 0.9395 \\
\hline & Temperature $\times$ Lineage & 2 & 1.147 & 2.615 & 0.0768 \\
\hline Random & Tree & 4 & 2.433 & N/A & N/A \\
\hline \multicolumn{6}{|c|}{ Rhododendron } \\
\hline \multirow[t]{3}{*}{ Fixed } & Temperature & 2 & 49.705 & 35.604 & $<0.0001^{*}$ \\
\hline & Lineage & 1 & 0.073 & 0.105 & 0.7461 \\
\hline & Temperature $\times$ Lineage & 2 & 3.768 & 2.699 & 0.0707 \\
\hline Random & Tree & 4 & 12.99 & N/A & N/A \\
\hline
\end{tabular}

${ }^{\mathrm{a}} \mathrm{N} / \mathrm{A}=$ not applicable.
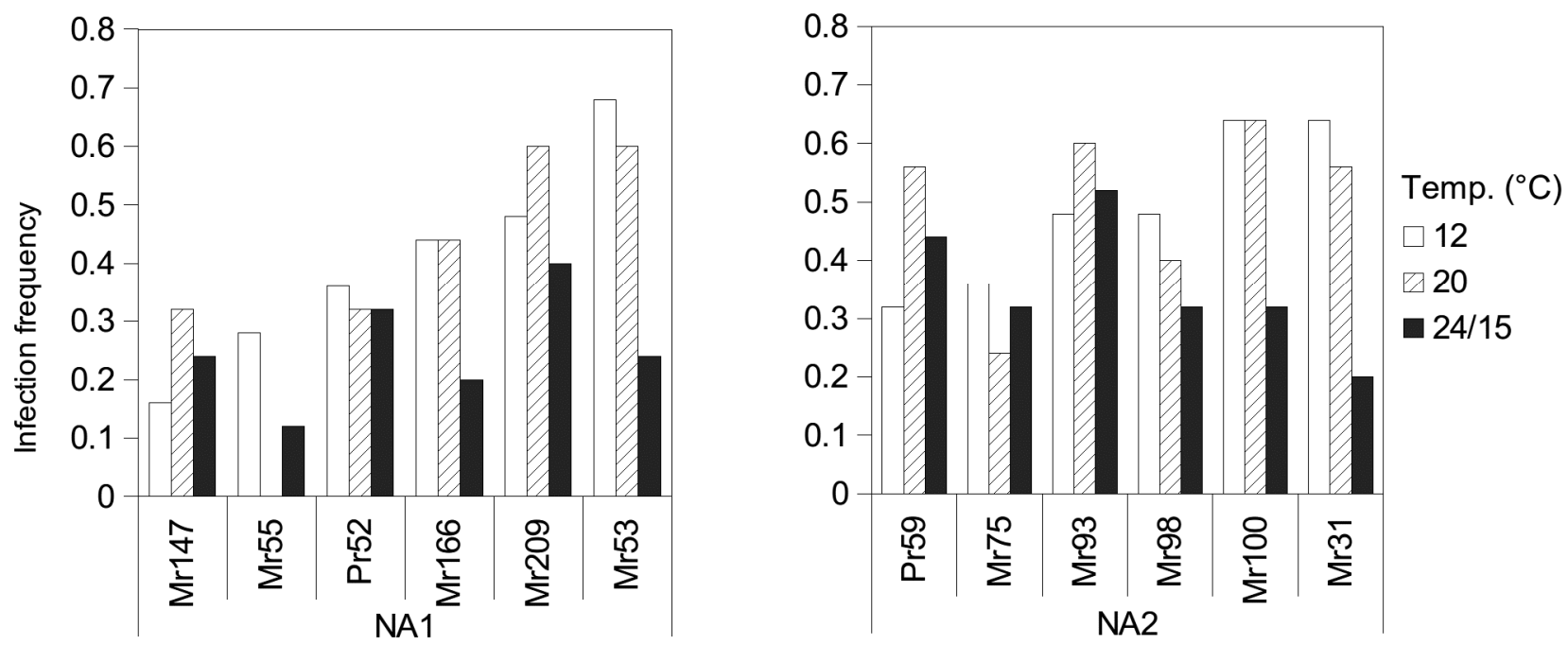

Fig. 7. Presence of lesions caused by mycelia of Phytophthora ramorum lineages NA1 and NA2 under three incubation conditions on unwounded bay laurel leaves. Mean value of 2.0 corresponds to $25 \%$ infection. 
fection (77). The relatively high rate of failed infection from mycelial inoculations in nonwounding inoculations may have arisen from the lack of a mechanism in mycelia to seek out stomata for entry points.

Overall, we found that temperature had a significant effect on lesion size but that the response varied depending on the host. At $20^{\circ} \mathrm{C}$, the optimal temperature for P. ramorum growth in vitro (76), the susceptibility of both rhododendron and bay laurel was very similar. There was some variability among isolates used to inoculate rhododendron but, generally, NA2 produced larger lesions than NA1 in both hosts at this temperature. At day and night temperature of 24 and $15^{\circ} \mathrm{C}$, respectively, a common temperature regime in coastal California in late spring, lesion sizes were reduced in both hosts equally but, at $12^{\circ} \mathrm{C}$, there was a significantly decreased quantitative susceptibility in rhododendron compared with bay laurel leaves, as shown by the smaller size of lesions on the former species. Interestingly, this suggests that different hosts may have a more labile relationship between susceptibility and temperature than previously thought. A significantly different response of clonal lineages to temperature has been shown for P. infestans (57). Synchrony has been observed between $P$. ramorum and hosts where sporulation by the pathogen and flushing by the host are both delayed at higher elevations and decreasing temperatures (16), and $P$. ramorum infection success has been related to phenology of the host (19). This is further evidence of the importance of temperature in the host-pathogen relationship. Other studies with $P$. ramorum have found close correlation in the responses of hosts, implying little host specialization by the pathogen (39); however, these were conducted at single temperatures and consequently did not reveal these differences between hosts. The majority of susceptibility trials are conducted at 18 to $20^{\circ} \mathrm{C}$, the optimal temperature for $P$. ramorum growth and sporulation in vitro; however, as shown by the variable host responses at the few temperatures included in our experiments, it is clear that a range of temperatures should be tested to gain full insight into host susceptibility.

The temperature-host interaction found here indicates that latitudinal and altitudinal gradients may have different effects on the rates of spread depending on host: in our case, for instance, whereas California bay laurel appears to be a viable host at cool, intermediate, and warmer temperatures, rhododendron was found to be a poor host at cooler temperatures. We hypothesize that the lack of spread of $P$. ramorum in natural settings of Northern continental Europe may be due, in part, to the long cooler periods characteristic of that region combined with the presence of rhododendron as the single major infectious host thus far. However, the spread of $P$. ramorum in southern Europe, where cold spells are shorter, may indeed be mediated by rhododendron. Conversely, the presence and infection of other infectious hosts in northern Europe may result in more successful outbreaks, were these hosts to act like California bay laurel. It is imperative to test susceptibility of widespread European or Eastern North American hosts at cool temperatures to improve our prediction of risk associated with outbreaks of $P$. ramorum outside of California, Oregon, and the British Isles, where infestations are currently underway.

The individuals within each clonal lineage are nearly identical with respect to the neutral genetic markers used to define the lineages. However, there was significant phenotypic variability among isolates in both lineages. Other studies have also observed significant variability among isolates $(39,40,64,75)$ and, in some cases, greater variability among NA1 isolates than NA2 was observed $(7,20)$. In contrast, we found similar variability among isolates within both lineages. We also found that there was a tendency toward reduced lesion size in successive trials using the same isolates, possibly indicating some kind of degeneration of the pathogen over time or a strong effect of time on inoculation results. We found some variation in the degree of degeneration among individual isolates in different trials; however, reduction in lesions size between trials was more or less consistent for both lineages overall. There is some evidence that the time of year can have an effect on the results of nonwounded zoospore inoculations $(13,14)$ but these trials occurred in relatively quick succession during the same season; therefore, we believe this to be an unlikely source of variation in this case. Other studies have also found differences between inoculation trials $(7,34,54)$.

Phenotypic instability has been described in cultures for $P$. ramorum where wild-type (WT) NA1 isolates degenerated into NWT phenotypes, defined by reduced growth rates, aggressiveness, and atypical colony morphology, more readily than those from the NA2 or EU1 lineages $(7,20,46)$. The greater variability in the NA1 lineage isolates than NA2 has been attributed to the high frequency of NWT isolates in that lineage (7). However, there is recent evidence that, within NA1, host provenance plays a major role in transition from WT to NWT, potentially due to epigenetic mechanisms $(39,46)$. Additionally, it has been suggested that phenotypic instability may be influenced by a culture's age, its growing environment $(7,42,49)$, and the accumulation of genetic mutations in longlived cultures (71).

The majority of NA1 isolates in this study were originally isolated from bay laurel, while all but one of the NA2 isolates were originally from rhododendron in nurseries, the exception being a single isolate from camellia (Mr106). Interestingly, one of the NA1 isolates that consistently produced the smallest lesions in both trials on rhododendron and camellia was Pr102, which was the only isolate that was originally isolated from coast live oak (46) (the other was Pr52, originally isolated from a rhododendron host in 2006). Similarly low aggressiveness has been found when Pr102 was used in other studies $(20,40)$. Although Pr102 exhibited WT growth, its reduced aggressiveness and provenance are traits shared with NWT isolates, indicating that there may by some relationship or causation, or that Pr102 is an isolate in transition.

Although it is not yet known how common these NWT phenotypes may be in natural populations, or how and why they develop, this information is vital for defining lineage traits. The cultures used in our experiments were all passed through leaf material at the same time prior to inoculation to ensure that cultures were viable, and only cultures that appeared to be healthy and relatively uniform in colony appearance (i.e., behaving like the WT phenotype) were used, in order to avoid biasing results by the use of isolates that had degenerated in culture. The inclusion or exclusion of NWT isolates in inoculation studies undoubtedly affect the overall assessment of the NA1 lineage's performance for certain traits but we do not yet know if this will represent the natural population more or less accurately. Interestingly, despite the altered morphology of NWT isolates, a lack of apparent effect on the production and size of sporangia in NWT isolates has been reported (7). However, more recent evidence suggests that the NWT phenotype develops over time (46). Consequently, even if the ability of the pathogen to gain access to the host via spores is not reduced in NWT phenotypes, they may yet produce smaller lesions once inside the host and, hence, reduce disease severity.

Several implications arise from the results presented here. First, if the NA2 lineage were to migrate from its nursery populations to forest ecosystems, our current models $(47,55,56)$ may have vastly underestimated the potential impact of this pathogen. Second, the interactions of host with pathogen lineage and temperature documented in this study indicate that rates of spread may differ depending on lineage and host available in natural ecosystems. These findings indicate that establishment of the NA2 lineage in California, where only the NA1 lineage is present in forests, could likely result in higher disease severity due to the higher susceptibility of California bay laurel (the major infectious host in that region) to NA2 isolates to zoospore infections. Currently, no regulations are enforced within the 14 infested California counties to prevent the introduction of NA2, EU1, and EU2 isolates (2). The risk associated with the introduction of EU lineages is even greater, due to the fact that they are of opposite mating type and, thus, sexual reproduction might occur. Establishment of a sexual population might lead to quicker adaptation through recombination and to the production of oospores known to survive at low temperatures (25). For example, oospores of $P$. infestans at its center of origin are thought 
to serve as the species' primary inoculum and survival structures $(22,30)$. In any case, emergence of any of the novel lineage in U.S. forests is expected to increase the negative impact of sudden oak death.

We conclude from our results that the phenotypic differences between lineages are heavily influenced by the representation of isolates used, host, and temperature. This highlights the need for the use of multiple isolates in susceptibility trials and the need for caution when interpreting results of inoculation studies. More comprehensive testing of larger samples of isolates and a wider range of hosts and environmental variables are required. Delineating how these factors interact to shape phenotype is vital for management of the pathogen and for constructing models of disease epidemiology. The work on the optimal temperatures for $P$. ramorum sporulation and growth $(21,76)$ has helped to inform predictive disease models $(55,68)$ and management strategies; however, lineage and isolate variability in relation to host populations and environmental conditions should also be incorporated for more comprehensive models. These additional trials are needed to make predictions of the range and impact of the disease in the future, especially in the face of climate change altering the geographic range of the pathogen

\section{Acknowledgments}

This study was funded by the United States Department of Agriculture (USDA) Forest Service, Pacific Southwest Research Station, and by the NSFEcology of Infectious Diseases program, Award Number 1115607. It was also supported by funds from USDA Agricultural Research Service CRIS Project 5358-22000-039-00D. We thank K. Graham, M. Larsen, M. Dimas, and M. Liu for lab assistance.

\section{Literature Cited}

1. Anacker, B. L., Rank, N. E., Hüberli, D., Garbelotto, M., Gordon, S., Harnik, T., Whitkus, R., and Meentemeyer, R. 2008. Susceptibility to Phytophthora ramorum in a key infectious host: Landscape variation in host genotype, host phenotype, and environmental factors. New Phytol. 177:756766.

2. Anonymous. 2008. List of regulated hosts and plants associated with Phytophthora ramorum. U.S. Department of Agriculture, Animal and Plant Health Inspection Service. Online publication. http://www.aphis.usda.gov/ plant_health/plant pest info/pram

3. Bates, D., Maechler, M., Bolker, B. M., and Walker, S. 2014. lme4: Linear Mixed-Effects Models using Eigen and S4. ArXiv e-print. J. Stat. Software. http://arxiv.org/abs/1406.5823

4. Brasier, C., and Webber, J. 2010. Sudden larch death. Nature 466:824-825.

5. Brasier, C. M., Denman, S., Brown, A., and Webber, J. F. 2004. Sudden oak death discovered on trees in Europe. Mycol. Res. 108:1108-1110.

6. Brasier, C. M., Franceschini, S., Vettraino, A. M., Hansen, E. M., Green, S., Robin, C., Webber, J. F., and Vannini, A. 2012. Four phenotypically and phylogenetically distinct lineages in Phytophthora lateralis. Fungal Biol. 116:1232-1249.

7. Brasier, C. M., Kirk, S. A., and Rose, J. 2006. Differences in phenotypic stability and adaptive variation between the main European and American lineages of Phytophthora ramorum. Pages 166-173 in: Progress in Research on Phytophthora Diseases of Forest Trees, 3rd Int. IUFRO Work Party Meeting. Friesling, Germany. C. M. Brasier, T. Jung, and W. Oswald, eds. Forest Research Alice Host Lodge, Farnham, Surrey, UK.

8. Brasier, C. M., Vettraino, A. M., Chang, T. T., and Vannini, A. 2010. Phytophthora lateralis discovered in an old growth Chamaecyparis forest in Taiwan. Plant Pathol. 59:595-603.

9. Chandelier, A., Heungens, K., and Werres, S. 2014. Change of mating type in an EU1 lineage isolate of Phytophthora ramorum. J. Phytopathol. 162:43-47.

10. Chastagner, G., Coats, K., and Elliott, M. 2011. Spread of Phytophthora ramorum to water, soil, and vegetation outside a nursery in Pierce County, Washington. (Abstr.) Phytopathology 101:S32.

11. Croucher, P. P., Mascheretti, S., and Garbelotto, M. 2013. Combining field epidemiological information and genetic data to comprehensively reconstruct the invasion history and the microevolution of the sudden oak death agent Phytophthora ramorum (Stramenopila: Oomycetes) in California. Biol. Invas. 15:2281-2297.

12. Davidson J. M., Werres, S., Garbelotto, M., Hansen, E. M., and Rizzo, D. M. 2003. Sudden oak death and associated diseases caused by Phytophthora ramorum. Plant Health Progress. Online publication. doi:10.1094/PHP-2003-0707-01-DG

13. De Dobbelaere, I., Heungens, K., and Maes, M. 2007. Effect of environmental and seasonal factors on the susceptibility of different Rhododendron species and hybrids to Phytophthora ramorum. Pages 95-97 in: Proc. Sudden Oak Death 3rd Sci. Sympos.
14. De Dobbelaere, I., Vercauteren, A., Speybroeck, N., Berkvens, D., Van Bockstaele, E., Maes, M., and Heungens, K. 2010. Effect of host factors on the susceptibility of Rhododendron to Phytophthora ramorum. Plant Pathol. 59:301-312.

15. Denman, S., Kirk, S. A., Brasier, C. M., and Webber, J. F. 2005. In vitro leaf inoculation studies as an indication of tree foliage susceptibility to Phytophthora ramorum in the UK. Plant Pathol. 54:512-521.

16. Desprez-Loustau, M.-L., Vitasse, Y., Delzon, S., Capdevielle, X., Marçais, B., and Kremer, A. 2010. Are plant pathogen populations adapted for encounter with their host? A case study of phenological synchrony between oak and an obligate fungal parasite along an altitudinal gradient. J. Evol. Biol. 23:87-97.

17. Dobrowolski, M., Tommerup, I., Shearer, B., and O'Brien, P. 2003. Three clonal lineages of Phytophthora cinnamomi in Australia revealed by microsatellites. Phytopathology 93:695-704.

18. Dodd, R., Hüberli, D., Douhovnikoff, V., Harnik, T., Afzal-Rafii, Z., and Garbelotto, M. 2005. Is variation in susceptibility to Phytophthora ramorum correlated with population genetic structure in coast live oak (Quercus agrifolia)? New Phytol. 165:203-214.

19. Dodd, R. S., Hüberli, D., Mayer, W., Harnik, T.Y., Afzal-Rafii, Z., and Garbelotto, M. 2008. Evidence for the role of synchronicity between host phenology and pathogen activity in the distribution of sudden oak death canker disease. New Phytol. 179 2:505-514.

20. Elliott, M., Sumampong, G., Varga, A., Shamoun, S. F., James, D., Masri, S., and Grünwald, N. J. 2011. Phenotypic differences among three clonal lineages of Phytophthora ramorum. For. Pathol. 41:7-14.

21. Englander, L., Browning, M., and Tooley, P. W. 2006. Growth and sporulation of Phytophthora ramorum in vitro in response to temperature and light. Mycologia 98:365-373.

22. Fernández-Pavía, S. P., Grünwald, N. J., Díaz-Valasis, M., Cadena Hinojosa, M., and Fry, W. E. 2004. Soil-borne oospores of Phytophthora infestans in central Mexico survive winter fallow and infect potato plants in the field. Plant Dis. 88:29-33.

23. Garbelotto, M., Barbosa, D., Mehl, H., and Rizzo, D. M. 2013. First report of the NA2 lineage of Phytophthora ramorum from an ornamental Rhododendron in the interior of California. Plant Dis. 98:849.

24. Garbelotto, M., Davidson, J. M., Ivors, K., Maloney, P. E., Hüberli, D., Koike, S. T., and Rizzo, D. M. 2003. Non-oak native plants are main hosts for sudden oak death pathogen in California. Calif. Agric. 57:18-23.

25. Garbelotto, M., and Hayden, K. J. 2012. Sudden Oak Death: Interactions of the Exotic Oomycete Phytophthora ramorum with Naive North American Hosts. Eukarot. Cell 11:1313-1323.

26. Goss, E. M., Carbone, I., and Grünwald, N. J. 2009. Ancient isolation and independent evolution of the three clonal lineages of the exotic sudden oak death pathogen Phytophthora ramorum. Mol. Ecol. 18:1161-1174.

27. Goss, E. M., Larsen, M., Chastagner, G. A., Givens, D. R., and Grünwald, N. J. 2009. Variation within the NA1 clonal lineage of Phytophthora ramorum from US nurseries reveals migration pathways. (Abstr.) Phytopathology 99:S45.

28. Goss, E. M., Larsen, M., Chastagner, G. A., Givens, D. R., and Grünwald, N. J. 2009. Population genetic analysis infers migration pathways of Phytophthora ramorum in US nurseries. PLoS Pathog. 5:e1000583.

29. Goss, E. M., Larsen, M., Vercauteren, A., Werres, S., Heungens, K., and Grünwald, N. J. 2011. Phytophthora ramorum in Canada: Evidence for migration within North America and from Europe. Phytopathology 101:166171.

30. Grünwald, N. J., and Flier W. G. 2005. The biology of Phytophthora infestans at its center of origin. Annu. Rev. Phytopathol. 43:171-190.

31. Grünwald, N. J., Garbelotto, M., Goss, E. M., Heungens, K., and Prospero, S. 2012. Emergence of the sudden oak death pathogen Phytophthora ramorum. Trends Microbiol. 20:131-138.

32. Grünwald, N. J., Goss, E. M., Ivors, K., Garbelotto, M., Martin, F. N., Prospero, S., Hansen, E., Bonants, P. J. M., Hamelin, R. C., Chastagner, G., Werres, S., Rizzo, D. M., Abad, G., Beales, P., Bilodeau, G. J., Blomquist, C. L., Brasier, C., Brière, S. C., Chandelier, A., Davidson, J. M., Denman, S., Elliott, M., Frankel, S. J., Goheen, E. M., de Gruyter, H., Heungens, K., James, D., Kanaskie, A., McWilliams, M. G., Man in 't Veld, W., Moralejo, E., Osterbauer, N. K., Palm, M. E., Parke, J. L., Sierra, A. M. P., Shamoun, S. F., Shishkoff, N., Tooley, P. W., Vettraino, A. M., Webber, J., and Widmer T. L. 2009. Standardizing the nomenclature for clonal lineages of the sudden oak death pathogen, Phytophthora ramorum. Phytopathology 99:792795.

33. Grünwald, N. J., Goss, E. M., Larsen, M. M., Press, C. M., McDonald, V. T., Blomquist, C. L., and Thomas, S. L. 2008. First report of the European lineage of Phytophthora ramorum on Viburnum and Osmanthus spp. in a California Nursery. Plant Dis. 92:314-314.

34. Grünwald, N. J., Goss, E. M., and Press, C. M. 2008. Phytophthora ramorum: A pathogen with a remarkably wide host range causing sudden oak death on oaks and ramorum blight on woody ornamentals. Mol. Plant Pathol. 9:729-740.

35. Grünwald, N. J., Kitner, M., McDonald, V., and Goss, E. M. 2008. Susceptibility in Viburnum to Phytophthora ramorum. Plant Dis. 92:210-214.

36. Hansen, E., Parke, J., and Sutton, W. 2005. Susceptibility of Oregon forest trees and shrubs to Phytophthora ramorum: A comparison of artificial inoc- 
ulation and natural infection. Plant Dis. 89:63-70.

37. Hansen, E. M., Reeser, P. W., Sutton, W., Winton, L. M., and Osterbauer, N. 2003. First report of A1 mating type of Phytophthora ramorum in North America. Plant Dis. 87:1267.

38. Hayden, K. J., Nettel, A., Dodd, R. S., and Garbelotto, M. 2011. Will all the trees fall? Variable resistance to an introduced forest disease in a highly susceptible host. For. Ecol. Manage. 261:1781-1791.

39. Hüberli, D., and Garbelotto, M. 2012. Phytophthora ramorum is a generalist plant pathogen with differences in virulence between isolates from infectious and dead-end hosts. For. Pathol. 42:8-13.

40. Hüberli, D., Harnik, T., Meshriy, M., Miles, L., Garbelotto, M. 2005. Phenotypic variation among Phytophthora ramorum isolates from California and Oregon. Pages 131-134 in: Proc. Sudden Oak Death Second Sci. Symp.: The State of Our Knowledge. S. J. Frankel, P. J. Shea, and M. I. Haverty, tech. coords. Pac. Southwest Res. Stn. For. Serv. U. S. Dep. Agric. Albany, CA. Gen. Tech. Rep. PSW-GTR-196.

41. Hüberli, D., Hayden, K. J., Calver, M., and Garbelotto, M. 2012. Intraspecific variation in host susceptibility and climatic factors mediate epidemics of sudden oak death in western US forests. Plant Pathol. 61:579-592.

42. Hüberli, D., Tommerup, I., Dobrowolski, M., Calver, M., and Hardy, G. 2001. Phenotypic variation in a clonal lineage of two Phytophthora cinnamomi populations from Western Australia. Mycol. Res. 105:1053-1064.

43. Ivors, K., Garbelotto, M., Vries, I., Ruyter-Spira, C., Hekkert, B., Rosenzweig, N., and Bonants, P. 2006. Microsatellite markers identify three lineages of Phytophthora ramorum in US nurseries, yet single lineages in US forest and European nursery populations. Mol. Ecol. 15:1493-1505.

44. Ivors, K. L., Hayden, K. J., Bonants, P. J. M., Rizzo, D. M., and Garbelotto, M. 2004. AFLP and phylogenetic analyses of North American and European populations of Phytophthora ramorum. Mycol. Res. 108:378-392.

45. Jiang, R. H. Y., Tyler, B. M., Whisson, S. C., Hardham, A. R., and Govers, F. 2006. Ancient origin of elicitin gene clusters in Phytophthora genomes. Mol. Biol. Evol. 23:338-351.

46. Kasuga, T., Kozanitas, M., Bui, M., Hüberli, D., Rizzo, D. M., and Garbelotto, M. 2012. Phenotypic diversification is associated with host-induced transposon derepression in the sudden oak death pathogen Phytophthora ramorum. PLoS One 7:e34728.

47. Kelly, M., Guo, Q., Liu, D., and Shaari, D. 2007. Modeling the risk of a new invasive forest disease in the United States: An evaluation of five environmental niche models. Comput. Environ. Urban Syst. 31:689-710.

48. Kleemann, J., Rincon-Rivera, L. J., Takahara, H., Neumann, U., Ver Loren van Themaat, E., van der Does, H. C., Hacquard, S., Stüber, K., Will, I., Schmalenbach, W., Schmelzer, E., and O'Connell, R. J. 2012. Sequential delivery of host-induced virulence effectors by appressoria and intracellular hyphae of the phytopathogen Colletotrichum higginsianum. PLoS Pathog. 8:e1002643. doi:10.1371/journal.ppat.1002643

49. Linde, C., Drenth, A., and Wingfield, M. 1999. Gene and genotypic diversity of Phytophthora cinnamomi in South Africa and Australia revealed by DNA polymorphisms. Eur. J. Plant Pathol. 105:667-680.

50. Manter, D. K., Kelsey, R. G., and Karchesy, J. J. 2007. Photosynthetic declines in Phytophthora ramorum-infected plants develop prior to water stress and in response to exogenous application of elicitins. Phytopathology 97:850-856.

51. Manter, D. K., Kolodny, E. H., Hansen, E. M., and Parke, J. L. 2010. Virulence, sporulation, and elicitin production in three clonal lineages of Phytophthora ramorum. Physiol. Mol. Plant Pathol. 74:317-322.

52. Mascheretti, S., Croucher, P. J. P., Kozanitas, M., Baker, L., and Garbelotto, M. 2009. Genetic epidemiology of the Sudden Oak Death pathogen Phytophthora ramorum in California. Mol. Ecol. 18:4577-4590.

53. Mascheretti, S., Croucher, P. J. P., Vettraino, A., Prospero, S., and Garbelotto, M. 2008. Reconstruction of the Sudden Oak Death epidemic in California through microsatellite analysis of the pathogen Phytophthora ramorum. Mol. Ecol. 17:2755-2768.

54. McDonald, V. T., and Grünwald, N. 2007. Evaluation of infection potential and sporulation of the three clonal lineages of Phytophthora ramorum on two Rhododendron cultivars. (Abstr.) Phytopathology 97:S73.

55. Meentemeyer, R., Rizzo, D., Mark, W., and Lotz, E. 2004. Mapping the risk of establishment and spread of sudden oak death in California. For. Ecol. Manage. 200:195-214

56. Meentemeyer, R. K., Cunniffe, N. J., Cook, A. R., Filipe, J. A. N., Hunter, R. D., Rizzo, D. M., and Gilligan, C. A. 2011. Epidemiological modeling of invasion in heterogeneous landscapes: Spread of sudden oak death in California (1990-2030). Ecosphere 2:art17. doi:10.1890/ES10-00192.1

57. Mizubuti, E., and Fry, W. 1998. Temperature effects on developmental stages of isolates from three clonal lineages of Phytophthora infestans. Phy- topathology 88:837-843.

58. Perez-Sierra, A., Alvarez, L. A., Vercauteren, A., Heungens, K., and AbadCampos, P. 2011. Genetic diversity, sensitivity to phenylamide fungicides and aggressiveness of Phytophthora ramorum on Camellia, Rhododendron and Viburnum plants in Spain. Plant Pathol. 60:1069-1076.

59. Prospero, S., Grünwald, N. J., Winton, L. M., and Hansen, E. M. 2009. Migration patterns of the emerging plant pathogen Phytophthora ramorum on the west coast of the United States of America. Phytopathology 99:739749 .

60. Prospero, S., Hansen, E. M., Grünwald, N. J., and Winton, L. M. 2007. Population dynamics of the sudden oak death pathogen Phytophthora ramorum in Oregon from 2001 to 2004. Mol. Ecol. 16:2958-2973.

61. R Core Team. 2013. R: A Language and Environment for Statistical Computing. R Foundation for Statistical Computing, Vienna, Austria.

62. Rizzo, D., Garbelotto, M., Davidson, J., Slaughter, G., and Koike, S. 2002. Phytophthora ramorum as the cause of extensive mortality of Quercus spp. and Lithocarpus densiflorus in California. Plant Dis. 86:205-214.

63. Rizzo, D. M., Garbelotto, M., and Hansen, E. M. 2005. Phytophthora ramorum: Integrative research and management of an emerging pathogen in California and Oregon forests. Annu. Rev. Phytopathol. 43:309-335.

64. Rosenzweig, N., Hüberli, D., Ivors, K., Olarte, R., Rizzo, D., and Garbelotto, M. 2005. The discovery and characterization of a unique group of isolates of Phytophthora ramorum from US nurseries. (Abstr.) Phytopathology 95:S90.

65. Tjosvold, S. A., and Chambers, D. L. 2006. Correlation of lesion size with percent lesion coverage on camellia and rhododendron leaves inoculated with Phytophthora ramorum. (Abstr.) Phytopathology 96:S114.

66. Tooley, P., Kyde, K., and Englander, L. 2004. Susceptibility of selected ericaceous ornamental host species to Phytophthora ramorum. Plant Dis. 88:993-999

67. Van Poucke, K., Franceschini, S., Webber, J. F., Vercauteren, A., Turner, J. A., McCracken, A. R., Heungens, K., and Brasier, C. M. 2012. Discovery of a fourth evolutionary lineage of Phytophthora ramorum: EU2. Fungal Biol. 116:1178-1191

68. Venette, R. C., and Cohen, S. D. 2006. Potential climatic suitability for establishment of Phytophthora ramorum within the contiguous United States. For. Ecol. Manage. 231:18-26.

69. Vercauteren, A., De Dobbelaere, I., Grünwald, N. J., Bonants, P., Van Bockstaele, E., Maes, M., and Heungens, K. 2010. Clonal expansion of the Belgian Phytophthora ramorum populations based on new microsatellite markers. Mol. Ecol. 19:92-107.

70. Vercauteren, A., Dobbelaere, I., Bockstaele, E., Maes, M., and Heungens, K. 2011. Genotypic and phenotypic characterization of the European A2 isolates of Phytophthora ramorum. Eur. J. Plant. Pathol. 129:621-635.

71. Vercauteren, A., Larsen, M., Goss, E., Grünwald, N.J., Maes, M., and Heungens, K. 2011. Identification of new polymorphic microsatellite markers in the NA1 and NA2 lineages of Phytophthora ramorum. Mycologia 103:1245-1249.

72. Vettraino, A. M., Sukno, S., Vannini, A., and Garbelotto, M. 2010. Diagnostic sensitivity and specificity of different methods used by two laboratories for the detection of Phytophthora ramorum on multiple natural hosts. Plant Pathol. 59:289-300

73. Webber, J. F., Mullett, M., and Brasier, C. M. 2010. Dieback and mortality of plantation Japanese larch (Larix kaempferi) associated with infection by Phytophthora ramorum. New Dis. Rep. 22:19.

74. Werres, S., and De Merlier, D. 2003. First detection of Phytophthora ramorum mating type A2 in Europe. Plant Dis. 87:1266-1266.

75. Werres, S., and Kaminski, K. 2005. Characterisation of European and North American Phytophthora ramorum isolates due to their morphology and mating behaviour in vitro with heterothallic Phytophthora species. Mycol. Res. 109:860-871.

76. Werres, S., Marwitz, R., Veld, W., De Cock, A., Bonants, P., De Weerdt, M. Themann, K., Ilieva, E., and Baayen, R. 2001. Phytophthora ramorum sp. nov., a new pathogen on Rhododendron and Viburnum. Mycol. Res. 105:1155-1165

77. Werres, S., and Riedel, M. 2013. How does Phytophthora ramorum infect Rhododendron leaves? Page 60 in: Proc. Sudden Oak Death 5th Sci. Sympos. S. J. Frankel, J. T. Kliejunas, K. M. Palmieri, and J. M. Alexander, tech. cords. U.S. Dep. Agric. For. Serv. Pac. Southwest Res. Stn. Albany, CA. Gen. Tech. Rep. PSW-GTR-243.

78. Zeller, K., Ismael, A., El-Assiuty, E., Fahmy, Z., Bekheet, F., and Leslie, J. 2002. Relative competitiveness and virulence of four clonal lineages of Cephalosporium maydis from Egypt toward greenhouse-grown maize. Plant Dis. $86: 373-378$. 